\title{
Perancangan Sistem Informasi Pelayanan Kesehatan (Studi Kasus : klinik Nayaka Era Husada Jakarta)
}

\author{
Ahmad Taufik ${ }^{1}$, Nanifadilah ${ }^{2}$ \\ Program Studi : Sistem Informasi STMIK Widuri Jakarta \\ Email : ${ }^{1}$ ahmadtaufik21@yahoo.co.id; ${ }^{2}$ fhadilOrenz@gmail.com
}

\begin{abstract}
ABSTRAK
Klinik Nayaka era husada 02 merupakan tempat praktek dokter umum dan gigi yang bersifat in house yaitu berada di dalam gedung BPJS Ketenagakerjaan Pusat yang beralamat di Jl. Jendral Gatot Subroto No. 79, RT.8/RW.2, Karet Semanggi, Kota Jakarta Selatan, Daerah Khusus Ibukota Jakarta 12930. Klinik Nayaka 02 hanya melayani pasien-pasien yang telah memiliki kartu kepersertaan nayaka. Sistem informasi pengolahan data pasien yang berjalan saat ini meliputi pendaftaran pasien, pemeriksaan, pengambilan obat serta pembuatan laporan. Akan tetapi sistem yang ada saat ini masih menggunakan semi komputer yaitu menggukan Ms.Excel, sehingga membuat pekerjaan dan pembuatan laporan menjadi kurang baik.

Dengan permasalahan yang dihadapi, maka klinik nayaka sangat perlu untuk memperbaiki sistem yang berjalan saat ini. Salah satu caranya adalah dengan mengganti sistem yang lama dengan menggunakan sistem yang telah terkomputerisasi. Untuk menjawab permasalahan diatas, penulis merancang sistem informasi pelayanan kesehatan dengan analisa menggunakan DAD, ERD, LRS, Normalisasi, Spesifikasi Basis Data dan Kamus Data. Sedangkan pembuatan aplikasinya menggunakan PHP dan MySQL.

Dengan dibuatnya sistem informasi pelayanan kesehatan pada klinik nayaka 02 yang terkomputerisasi dapat meningkatkan efisiensi dan efektifitas proses pada klinik serta mempermudah dalam pembuatan laporan.
\end{abstract}

Kata Kunci : Sistem Informasi, Pelayanan Kesehatan, PHP dan MySQL. 


\section{Pendahuluan}

Terwujud dan terpeliharanya keadaan sehat merupakan harapan semua pihak. Hal ini tidak hanya diinginkan individu, tetapi juga oleh keluarga, kelompok, organisasi, perusahaan dan seluruh anggota masyarakat. Untuk dapat mewujudkan keadaan sehat ada beberapa hal yang perlu ditempuh. Salah satu diantaranya yang dinilai mempunyai peranan yang cukup penting dan strategis yaitu dengan menyelenggarakan pelayanan kesehatan. Dalam mengantisipasi biaya kesehatan yang semakin melangit di perusahaan-perusahaan, PT. Nayaka Era Husada (NEH) ikut berpartisipasi dalam menyiapkan program pelayanan kesehatan yang bersifat fleksibel. Sifat fleksibel ini sengaja dirancang sedemikian rupa agar para pimpinan perusahaan dapat menyelenggarakan sesuai dengan kemampuan atau kondisi keuangan perusahaan, namun tetap mengacu pada Permenaker nomor 1 Tahun 1998. Dengan demikian perusahaan akan tetap bisa mendapatkan kelonggaran dalam mengatur budget dan programmya guna meningkatkan produktivitas kerja karyawan melalui program Pemeliharaan Kesehatan.

Klinik merupakan salah satu tempat didalamnya terjadi proses pertukaran informasi dengan kolaborsi mobilitas dan integrasi data, baik dalam klinik itu sendiri atau dalam hubungan dengan dinas kesehatan yang membawa dalam penanganan pasien, ketersedian rekam medis, dan kepuasaan pasien. akan pelayanan yang diberikan oleh klinik sangat dipengaruhi oleh kecepatan dan ketepatan dari para petugas dalam manangani pasien dimulai pasien mendaftarkan dirinya diloket hingga pasien tersebut diperiksa oleh tenaga medis atau nonmedis sampai mendapatkan obat untuk peyakit yang dikeluhnya.

Untuk saat ini sistem yang digunakan dalam memberikan pelayanan terhadap pasiennya klinik Nayaka 02 belum terbilang maksimal dikarenakan lamanya pencarian data pasien dan pendaftaran yang masih manual dengan di input ke exel.

\section{Tinjauan Pustaka \\ Sistem Basis Data}

Menurut Thommas Connolly, Carolyn Begg (2010: 15), bahwa : "basis data adalah kumpulan data yang terbagi dan terhubung secara logikal dan deskripsi dari data yang dirancang untuk memenuhi kebutuhan informasi suatu organisasi".

Menurut Abdul Kadir (2009: 17 ) mengatakan bahwa : "DBMS (Data Base Management System) adalah suatu perangkat lunak yang ditunjukan untuk menangani penciptaan, pemeliharaan, dan pengendalian akses data. Dengan menggunakan perangkat lunak ini pengelolaan data menjadi lebih mudah dilakukan".

Tiga (3) bahasa yang digunakan dalam DBMS yaitu :

1. Data Definition Language (DDL), Hasil dari perintah DDL adalah suatu set dari tabel yang disimpan dalam file khusus yang disebut data dictionary/directory. Fungsi DDL

2. Data Manipulation Language (DML), DML merupakan bahasa yang memperbolehkan pemakai untuk akses atau manipulasi data seperti yang telah diorganisasikan sebelumnya dalam model data yang tepat. Fungsi DML melakukan manipulasi dan pengambilan data dari suatu database management system.

3. Data Control Language (DCL), DCL berfungsi melakukan pengamanan database. Hal ini akan dibahas secara khusus dalam keamanan basis data (Security Database).

\section{Beberapa komponen DBMS :}

1. Perangkat keras (Hardware), DBMS dan aplikasiaplikasinya memerlukan hardware untuk beroperasi. Hardware tersebut antara lain terdiri beberapa PC (personal computer) yang terhubung ke satu mainframe yang terintegrasi dalam sebuah jaringan.

2. Perangkat lunak (Software), Komponen software terdiri dari DBMS berupa SQL Server 2008, dan aplikasi yang berjalan dengan operation system (OS) dengan bantuan jaringan.

3. Data, Komponen terpenting pada DBMS dan pemakai (end user) adalah data. Data digunakan sebagai jembatan anatara hardware dan software dengan komponen manusia sebagai pengguna.

4. Prosedur, Prosedur menunjuk pada instruksi dan aturan yang mempengaruhi pendesainan dan penggunaan dari database. Prosedur digunakan oleh para pengguna sistem yang mengatur database sebagai arahan untuk menggunakan dan menjalankan sistem.

5. Manusia , Orang-orang yang berhubungan dengan sistem antara lain :

\section{Pelayanan Kesehatan}

Menurut Dr. Grace E. C. Korompis MHSM ( 2015 : 138 ) bahwa : "Ketersediaan sarana pelayanan dan tenaga kesehatan yang berkualitas serta anggaran yang memadai dapat mempengaruhi status kesehatan masyarakat. Pengetahuan dan keterampilan petugas kesehatan yang diimbangi dengan kelengkapan sarana dapat memberikan 
pelayanan yang maksimal sehingga mampu mengurangi atau mengatasi masalah kesehatan yang timbul di masyarakat".

Menurut Dr.Muhammad Muhyi dkk ( 2016 : 4 ) Menyatakan bahwa : "Kesehatan adalah hal penting dalam kehidupan manusia. Badan yang sehat akan mendukung aktivitas seseorang dalam melaksanakan tugasnya".

Dalam sistem pelayanan kesehatan dapat mencakup pelayanan dokter, pelayanan keperawatan dan pelayanan kesehatan masyarakat. Dokter merupakan subsistem dari pelayanan kesehatan. Subsistem pelayanan kesehatan tersebut memiliki tujuan masing-masing dengan tidak meninggalkan tujuan umum dari pelayanan kesehatan.

Dalam pelayanan kesehatan terdapat tiga bentuk yaitu, primary health care, (pelayanan kesehatan tingkat pertama),secondary care (pelayanan kesehatan tingkat kedua), dan tertiary health services (pelayanan kesehatan tingkat ketiga).

1. Primary health care ( pelayanan kesehatan tingkat pertama ), Pelayanan kesehatan ini dibutuhkan atau dilaksanakan pada masyarakat yang memiliki masalah ringan atau masyarakat sehat ingin mendapatkan peningkatan kesehatan agar menjadi optimal dan sejahtera sehinga sifat pelayanan kesehatan adalah layanan kesehatan dasar. Pelayanan kesehatan ini dapat dilaksanakan oleh puskesmas, klinik dll.

2. Secondary health care ( pelayanan kesehatan tingkat kedua ), Bentuk pelayanan kesehatan ini diperlukan bagi masyarakat yang membutuhkan perawatan dirumah sakit dan tersedia tenaga spesialis atau sejenisya.

3. Tritiary healt service ( pelayanan kesehatan tingkat ketiga ), Tingkat pelayanan keehatan ini digunakan apabila tingkat pertama dan kedua tidak lagi digunakan. Pelayanan ini membutuhkan tenaga-tenaga yang ahli atau spesialis dan sebagai rujukan utama seperti rumah sakit $A$ atau $B$.

\section{XAMPP}

Menurut Bunafit Nugroho (2008: 2) "XAMPP adalah suatu bundel web server yang populer digunakan untuk coba-coba di Windows karena kemudahan instalasinya. Bundel program open source tersebut berisi antara lain server web Apache, interpreter PHP, dan basis data MySQL. Setelah menginstall XAMPP,kita bisa memulai pemrograman
PHP di komputer sendiri maupun mencoba menginstall aplikasi-aplikasi web."

Menurut Madcoms (2016: 2 ) “PHP (Hypertext Preprocessor) adalah bahasa script yang dapat ditanamkan atau disisipkan ke dalam HTML.Php banyak juga dipakai membuat program situs web dinamis. Php adalah bahasa pemrograman script server-side yang didesain untuk pengembangan web. Disebut bahasa pemrograman server-side karena php diproses pada komputer server."

PHP ini bersifat open source sehingga dapat dipakai secara cuma-cuma dan mampu lintas platform, yaitu dapat berjalan pada sistem operasi Windows maupun Linux. PHP juga dibangun sebagai modul pada web server apache dan sebagai binary yang dapat berjalan sebagai CGI.

\section{Hasil dan Pembahasan}

\section{Diagram Konteks}

Diagram konteks adalah bagian dari data flow diagram atau yang berfungsi memetakan model lingkungan, yang dipresentasikan dengan lingkungan tunggal yang mewakili keseluruha sistem. Di bawah ini gambar diagram konteks Rancangan Sistem Informasi pelayanan kesehatan klinik nayaka 02.

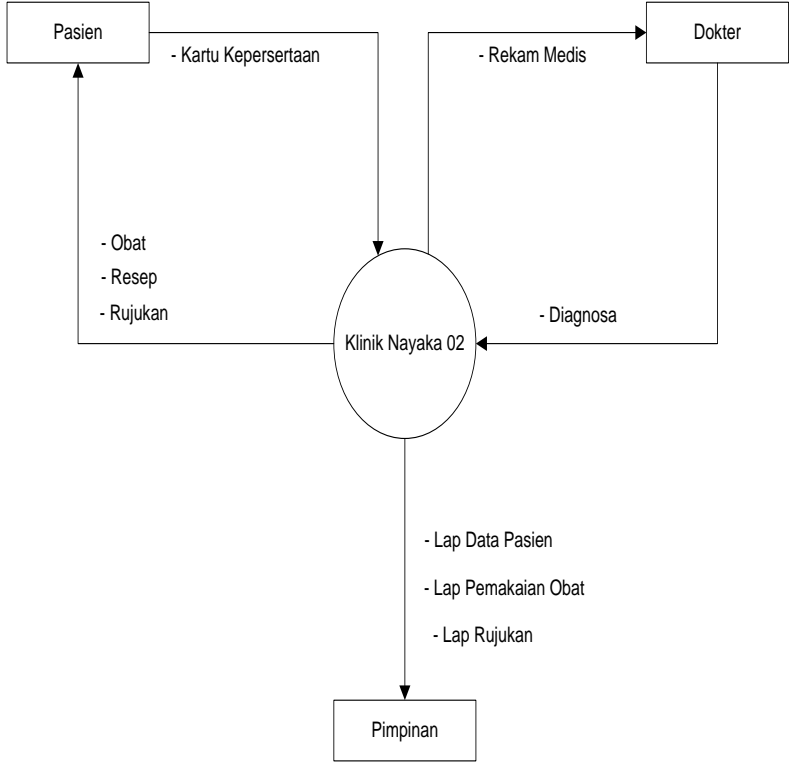

\section{Gambar3.1 Diagram Konteks}

\section{Diagram Overview}

Dibawah ini gambar diagram overview Rancangan Sistem Informasi Pelayan Kesehatan Klinik Nayaka 02. 


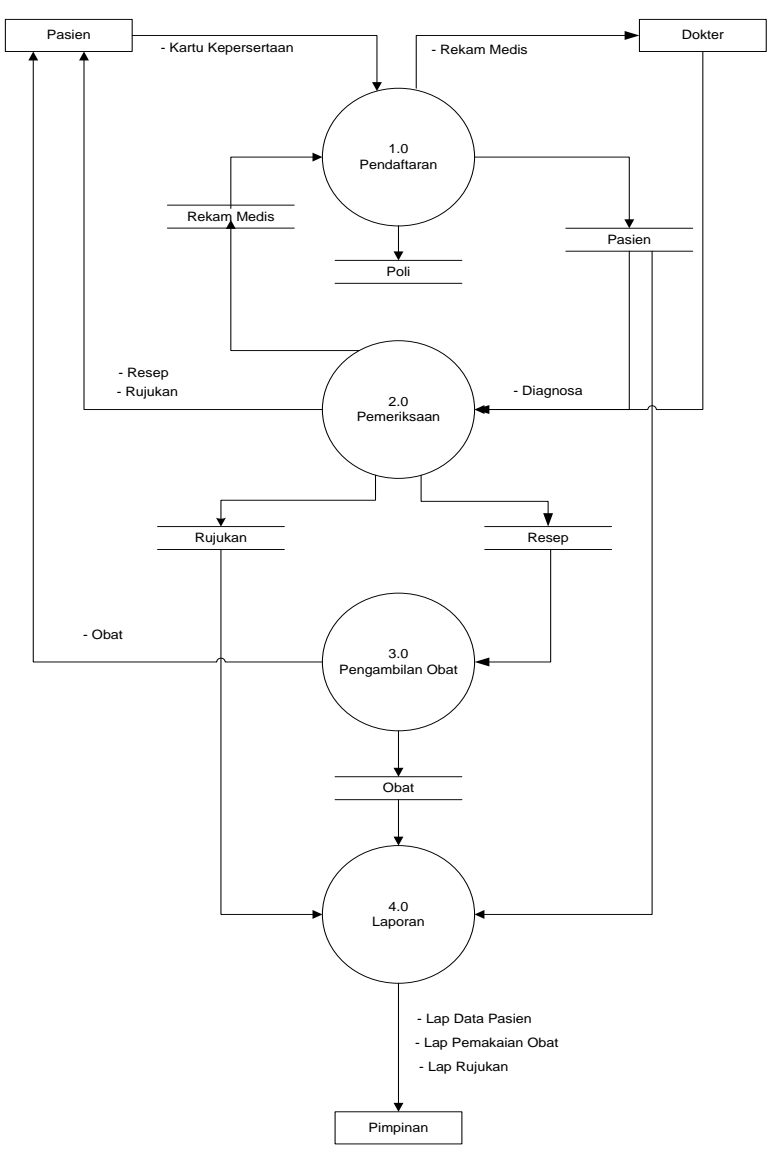

Gambar 3.2 Diagram Overview

Entity Relationship Diagram ( ERD )

Merupakan suatu model untuk menjelaskan hubungan antar data dalam basis data berdasarkan objek-objek dasar data yang mempunyai hubungan antar relasi.

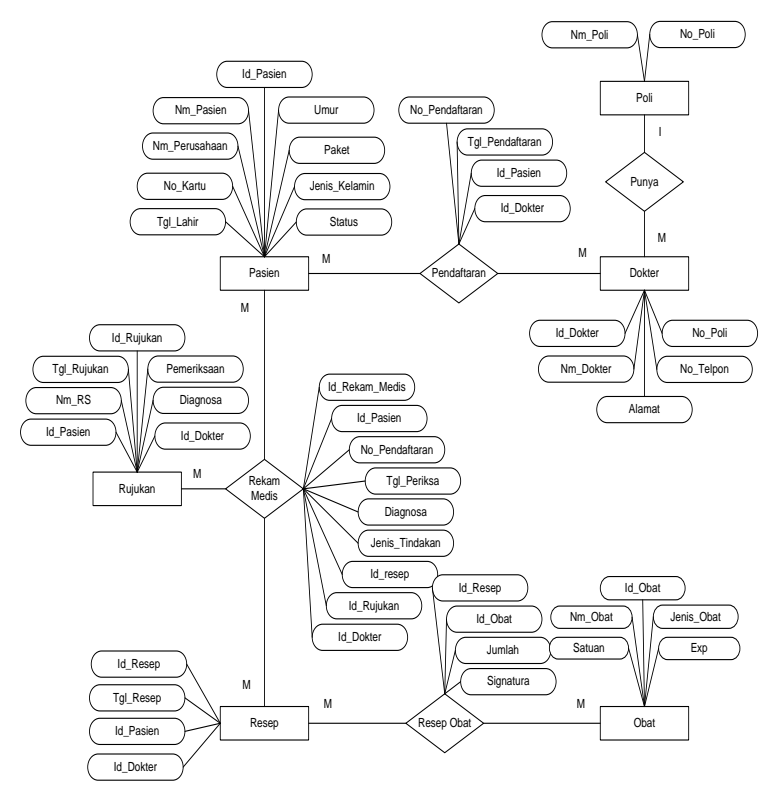

Gambar 3.3 Entity Relationship Diagram

\section{Kamus Data}

Kamus

data

digunakanuntukmendefinisikan data yang mengalir dalam suatu sistem, yaitu tentang data yang masukke system dan tentang informasi yang dibutuhkan oleh sistem, dan di peroleh dari ERD.

A.

Alamat

D.

$$
\begin{aligned}
& \text { :*Alamat* }^{*} \text { :\{Varchar\} } 30
\end{aligned}
$$

Diagnosa

:*diagnosa*

:\{Varchar $\} 25$

E.

Exp

$$
\begin{aligned}
& : * \operatorname{Exp}^{*} \\
& :\{\text { Date }\} 10
\end{aligned}
$$

I.

$\begin{array}{ll}\text { Id_Dokter } & : * \text { Id Dokter* } \\ & :\{\text { Int } 5 \\ & : * \text { Id Pasien* } \\ & :\{\text { Int } 5 \\ \text { Id_Pasien } & : \text { Id Rujukan* } \\ & :\{\text { Int } 5 \\ \text { Id_Rujukan } & : \text { Id Rekam Medis* } \\ & :\{\text { Int } 5 \\ \text { Id_Rekam_Medis } & : * \text { Id Resep* } \\ & :\{\text { Int } 5 \\ \text { Id_Resep } & : \text { Id Obat* } \\ & :\{\text { Int } 5\end{array}$

J.

Jenis_Kelamin

:*Jenis Kelamin* 


$$
\begin{aligned}
& \text { Jumlah }:\{\text { Varchar }\} 1 \\
&: * \text { Jumlah* } \\
&:\{\text { Int }\} 5 \\
& \text { Jenis_Obat }: * \text { Jenis Obat* } \\
&:\{\text { Varchar }\} 15 \\
& \text { Jenis_Tindakan } \\
&: * \text { Jenis Obat* } \\
&:\{\text { Varchar }\} 30
\end{aligned}
$$

N.

Nm_Dokter

:*Nama Dokter

: $\{$ Varchar $\} 25$

No Telpon : : $\quad$ No Telpon*

:*No kartu*

\section{Rancangan Layar}

Berikutrancanganlayarmasukandankeluar anuntuktampilan menu pada sistem informasi pelayanan kesehatan klinik nayaka era husada 02 yang berbasis desktop.

1. Login

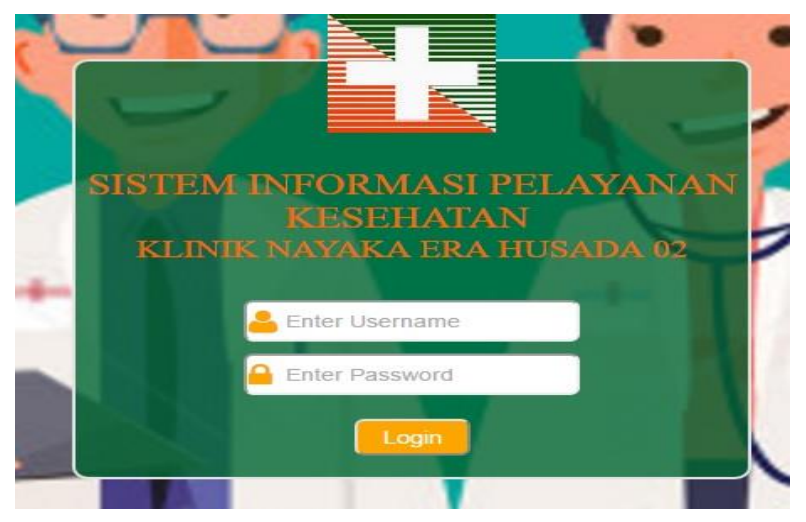

Gambar 3.5 Meu Login

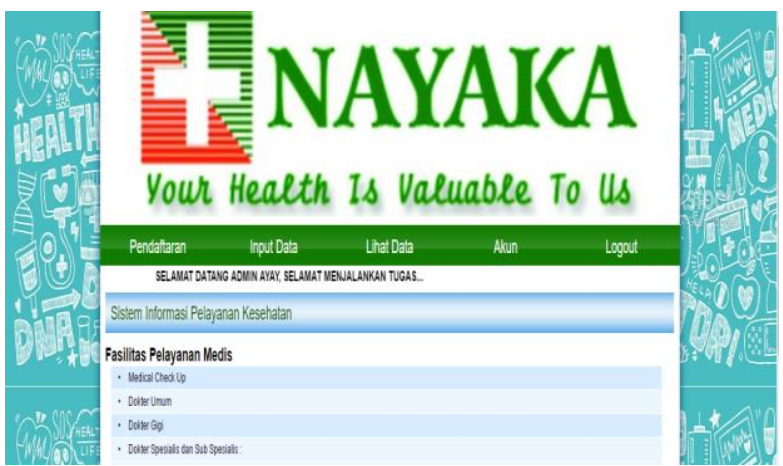

Gambar 3.6 Menu Utama

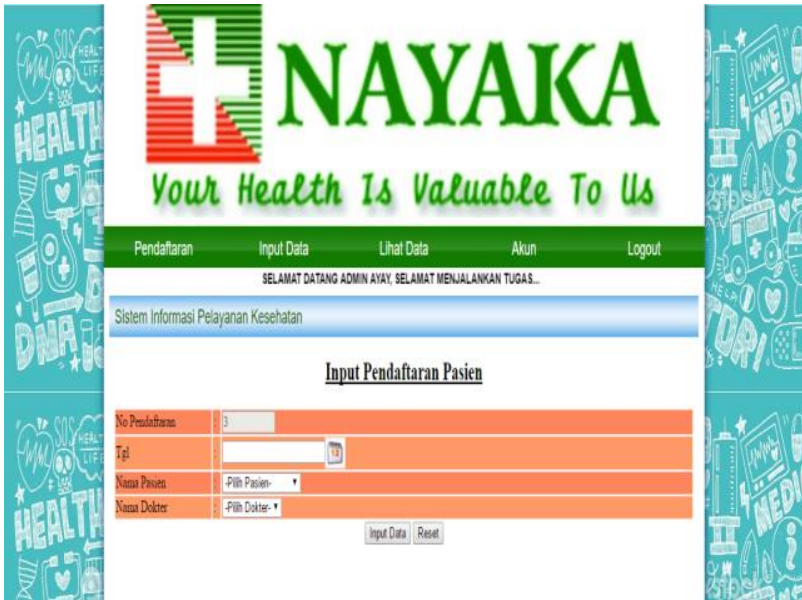

Gambar 3.6 Input data Pasien

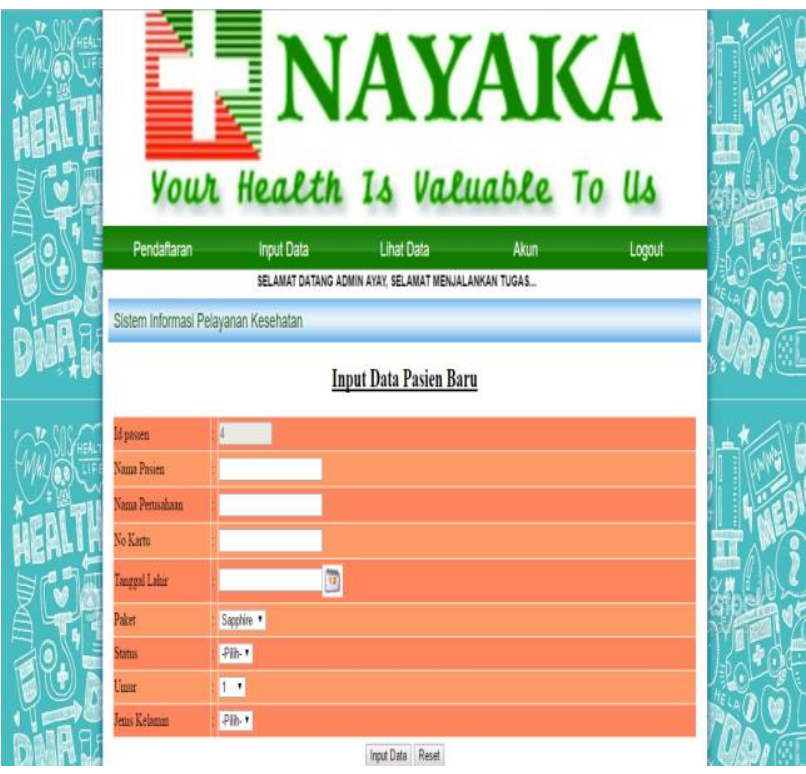

Gambar 3.7 Pendaftaran

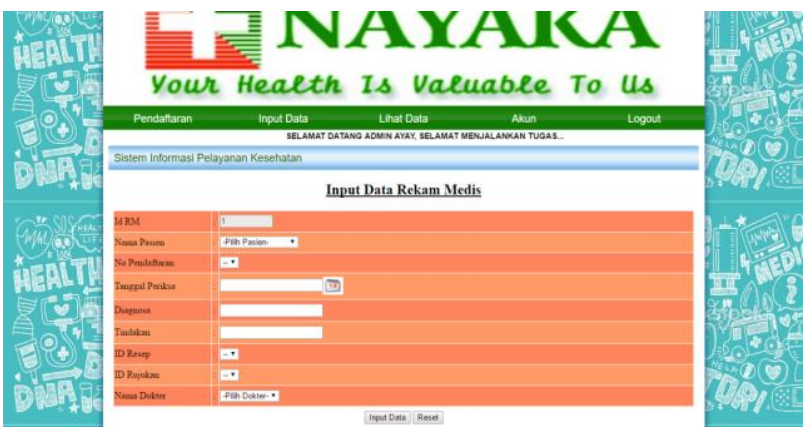

Gambar 3.8 Input Rekam Medis 


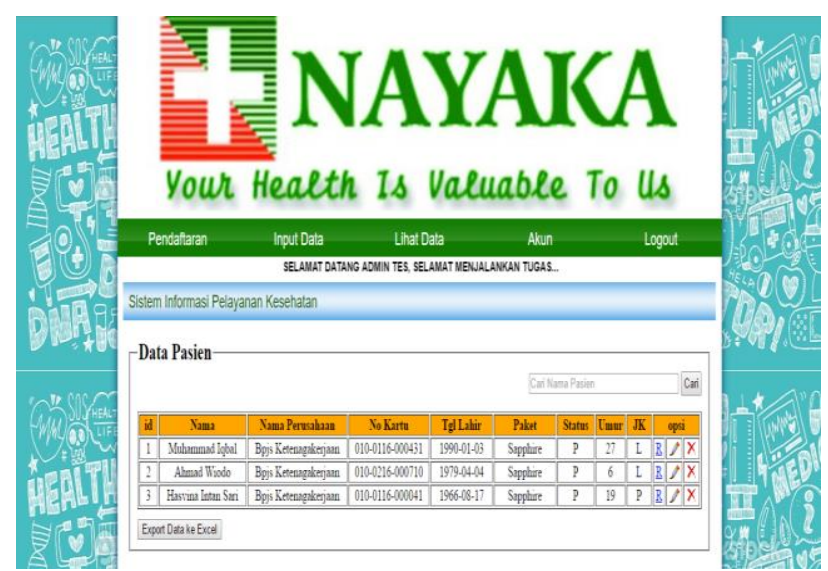

Gambar 3.9 Lihat Data Pasien

\section{Kesimpulan}

Setelah melakakukan perancangan maka dapat di tarik kesimpulan sebagai berikut :

1. Dalam penyajian informasi mengenai sistem pelayanan kesehatan pada klinik nayaka 02, akan menghasilkan suatu informasi yang cepat, tepat dan lebih efisien.

2. Sistem informasi yang dibuat dapat mempermudah pendataan pasien,
3. pencarian data pasien, penyimpanan rekam medis, pencarian rekam medis, dan Pembuatan laporan.

\section{DAFTAR PUSTAKA}

Al Fatta, Hanif. 2007. Analisis \& Perancangan Sistem Informasi :Untuk keunggulan bersaing perusahaan \& organisasi modern.

Yogyakarta :Andi

Sianipar, Riamon Hasiholan. 2015. HTML 5 dan CSS 3 Belajar Dari Kasus.Bandung :Informatika Sutabri, Tata. 2012. Analisis Sistem Informasi. Yogyakarta :Andi Tantra, Rudy. 2012. Manajemen Proyek Sistem Informasi :Bagaimana mengelola proyek system informasi secara efektif \& efisien.

Yogyakarta :Andi

Taufiq, Rohmat. 2013. Sistem Informasi

Manajemen. Yogyakarta.Graha IImu

Yakub. 2012. Pengantar Sistem Informasi. Grahallmu

Connolly, T., Begg, C. 2010.Database Systems: a practical approach to design, implementation, and management. 5th Edition. America: Pearson Education

Kadir, Abdul. 2009. Dasar Perancangan \& Implementasi : Database Relasional. Yogyakarta :Andi

Korompis, Grace E. C. 2015. Organisasi \& Manajemen Kesehatan.Jakarta : EGC Madcoms, 2016.Pemrograman PHP dan MySQL untuk Pemula.Yogyakarta :Andi

Muhyi, Muhammad dkk.2016.Learning Through Movement.Yogyakarta :Andi Nugroho Bunafit. 2008.

Latihan Membuat Aplikasi Web PHP dan Mysql dengan Dreamwaver. Yogyakarta :Gava Media 